Article

\title{
The Microstructure and Mechanical Properties of Ferritic-Martensitic Steel EP-823 after High-Temperature Thermomechanical Treatment
}

\author{
Igor Litovchenko ${ }^{1, *(\mathbb{D})}$, Kseniya Almaeva ${ }^{1}$, Nadezhda Polekhina ${ }^{1}$, Sergey Akkuzin ${ }^{1}$, Valeria Linnik ${ }^{1}$, \\ Evgeny Moskvichev ${ }^{1}\left(\mathbb{D}\right.$, Vyacheslav Chernov $^{2}$ and Maria Leontyeva-Smirnova ${ }^{2}$
}

1 Institute of Strength Physics and Materials Science of the Siberian Branch of the Russian Academy of Sciences (ISPMS SB RAS), 2/4 pr. Akademicheskii, 634055 Tomsk, Russia; kseni_ya_almaeva@mail.ru (K.A.); nadejda89tsk@yandex.ru (N.P.); akkuzin.spti@mail.ru (S.A.); lera.linnik.1999@mail.ru (V.L.); em_tsu@mail.ru (E.M.)

2 JSC “A. A. Bochvar High-Technology Research Institute of Inorganic Materials”, 5 Rogov St., 123060 Moscow, Russia; vmchernov@bochvar.ru (V.C.); mvleonteva-smirnova@bochvar.ru (M.L.-S.)

* Correspondence: litovchenko@spti.tsu.ru; Tel.: +7-3822-286900

check for updates

Citation: Litovchenko, I.; Almaeva,

K.; Polekhina, N.; Akkuzin, S.; Linnik, V.; Moskvichev, E.; Chernov, V.; Leontyeva-Smirnova, M. The Microstructure and Mechanical Properties of Ferritic-Martensitic Steel EP-823 after High-Temperature Thermomechanical Treatment. Metals 2022, 12, 79. https://doi.org/ $10.3390 /$ met12010079

Academic Editor: Soran Birosca

Received: 1 December 2021

Accepted: 27 December 2021

Published: 4 January 2022

Publisher's Note: MDPI stays neutral with regard to jurisdictional claims in published maps and institutional affiliations.

Copyright: (C) 2022 by the authors. Licensee MDPI, Basel, Switzerland. This article is an open access article distributed under the terms and conditions of the Creative Commons Attribution (CC BY) license (https:// creativecommons.org/licenses/by/ $4.0 /)$.

\begin{abstract}
The effect of high-temperature thermomechanical treatment (HTMT) with plastic deformation by rolling in austenitic region on the microstructure and mechanical properties of $12 \%$ chromium ferritic-martensitic steel EP-823 is investigated. The features of the grain and defect microstructure of steel are studied by Scanning Electron Microscopy with Electron Back-Scatter Diffraction (SEM EBSD) and Transmission Electron Microscopy (TEM). It is shown that HTMT leads to the formation of pancake structure with grains extended in the rolling direction and flattened in the rolling plane. The average sizes of martensitic packets and ferrite grains are approximately 1.5-2 times smaller compared to the corresponding values after traditional heat treatment (THT, which consists of normalization and tempering). The maximum grain size in the section parallel to the rolling plane increases up to more than $80 \mu \mathrm{m}$. HTMT leads to the formation of new sub-boundaries and a higher dislocation density. The fraction of low-angle misorientation boundaries reaches up to $\approx 68 \%$, which exceeds the corresponding value after HTMT (55\%). HTMT does not practically affect the carbide subsystem of steel. The mechanical properties are investigated by tensile tests in the temperature range $20-700{ }^{\circ} \mathrm{C}$. It is shown that the values of the yield strength in this temperature range after HTMT increase relative to the corresponding values after THT. As a result of HTMT, the elongation decreases. A significant decrease is observed in the area of dynamic strain aging (DSA). The mechanisms of plastic deformation and strengthening of ferritic-martensitic steel under the high-temperature thermomechanical treatments are also discussed.
\end{abstract}

Keywords: ferritic-martensitic steels; high temperature thermomechanical treatment; electron microscopy; microstructures; mechanical properties

\section{Introduction}

Ferritic-martensitic steels with a chromium content of $9-12 \%$ are considered as the candidate structural materials for nuclear and thermonuclear reactors of a new generation. This is due to the achieved complex of physical and mechanical properties, such as high values of heat resistance, low swelling (compared with austenitic steels), high resistance to radiation and helium embrittlement and other advantages [1-3]. The efficiency of a nuclear reactor and the possibility of increasing its operating temperature are determined, among other things, by the long-term strength properties of its structural materials. Both long-term and short-term strength properties of ferritic-martensitic steels are controlled by the elemental composition, microstructure features (dimensions of tempered martensite packets, volume fraction of ferrite, dislocation density), composition, dimensions and 
spatial distribution of carbide (carbonitride) phases [4-11]. Steels of this class are most thoroughly investigated in the structural state after normalization and tempering; this processing is referred to here as a traditional heat treatment (THT). After this treatment, the microstructure of the steels represents tempered martensite and ferritic grains with coarse carbides of $\mathrm{M}_{23} \mathrm{C}_{6}$ type (M-Fe, $\mathrm{Cr}, \mathrm{Mn}$ ) and fine submicron particles of carbonitrides of $\mathrm{MX}$ type $(\mathrm{M}-\mathrm{V}, \mathrm{Nb}, \mathrm{Ta} ; \mathrm{X}-\mathrm{C}, \mathrm{N})$ [4-8]. It was shown [4-7,12-21] that various thermomechanical treatments, including those using plastic deformation in the austenitic region, make it possible to effectively change the above-mentioned parameters of the microstructure and the carbide subsystem of ferritic-martensitic steels. These changes mainly consist of a smaller width of martensitic packets and lamella, an increased dislocation density, a decreased size of coarse phases of the $\mathrm{M}_{23} \mathrm{C}_{6}$ type and an increased dispersion of nanoscale carbides (carbonitrides) of the MX type [11,12,15-17,22-28].

The $12 \%$ chromium steel EP-823 is a representative of the ferritic-martensitic class of steels. This steel is currently being considered as one of the candidates for Generation IV nuclear reactors [29-31]. It is planned to be used as a material for fuel cladding shells for the Russian innovative fast neutron reactor core BREST OD-300 [32,33]. The influence of thermomechanical treatments on its microstructure and mechanical properties remains poorly understood. This paper presents the results of investigation of the effect of hightemperature thermomechanical treatment (HTMT) of this steel on the features of its grain and defect microstructure and the carbide subsystem, as well as short-term mechanical properties under tensile testing in a wide temperature range in comparison with THT.

\section{Materials and Methods}

The starting material was a Russian $12 \%$ chromium ferritic-martensitic steel EP-823 with a chemical composition shown in Table 1 . The THT was performed by normalization at $1100{ }^{\circ} \mathrm{C}$ for $1 \mathrm{~h}$ followed by tempering at $720{ }^{\circ} \mathrm{C}$ for $3 \mathrm{~h}$. The HTMT consisted of heating at $1100{ }^{\circ} \mathrm{C}$, holding for $1 \mathrm{~h}$, hot plastic deformation by rolling to a value of $\varepsilon \approx 50 \%$ per 1 pass, and subsequent water quenching followed by tempering at $720{ }^{\circ} \mathrm{C}$ for $1 \mathrm{~h}$. The initial sample thickness was $2 \mathrm{~mm}$. Heating was carried out in a tubular electric furnace of the T-40/600 type (Plant "LETO", Tula, Russia). The rolling mill was maintained at room temperature. The time before the transfer of the sample from the furnace to the rolling mill was about 5 s, so the actual deformation temperature was lower than that in the furnace.

Table 1. Elemental composition of EP-823 steel, Fe-base, wt. \%.

\begin{tabular}{lcccccccccccccc}
\hline Element & $\mathbf{C}$ & $\mathbf{C r}$ & $\mathbf{M n}$ & $\mathbf{M o}$ & $\mathbf{N b}$ & $\mathbf{V}$ & $\mathbf{W}$ & $\mathbf{N i}$ & $\mathbf{N}$ & $\mathbf{S i}$ & $\mathbf{C e}$ & $\mathbf{T i}$ & $\mathbf{B}$ & $\mathbf{A l}$ \\
\hline Comp. & 0.14 & 11.56 & 0.58 & 0.74 & 0.40 & 0.34 & 0.68 & 0.68 & 0.03 & 1.09 & 0.10 & 0.01 & 0.006 & 0.02 \\
\hline
\end{tabular}

The microstructural characterization was performed using a Tescan MIRA 3 LMU field emission scanning electron microscope (SEM) (TESCAN ORSAY HOLDING, Brno, Czech Republic) and an Oxford Instruments Nordlys F electron back-scatter diffraction (EBSD) detector (Oxford Instruments, High Wycombe, UK). Some samples were etched in a Vivela etchant to reveal the structure and dispersed particles. The SEM samples for EBSD were prepared by mechanical polishing followed by ion milling as a final polishing step. Ion polishing was performed using a Technoorg Linda SEMPrep 2 system (Technoorg Linda Co., Ltd., Budapest, Hungary). After HTMT, the EBSD images were taken in the section parallel to the rolling plane (perpendicular to normal direction (ND)) and in the longitudinal section (perpendicular to transverse direction (TD)). The EBSD data were obtained with the step sizes of 200 and $50 \mathrm{~nm}$ in the section parallel to the rolling plane and $175 \mathrm{~nm}$ in the longitudinal section. The microstructure was analyzed using the Oxford Instruments AZtec software (version 3.1, Oxford Instruments, High Wycombe, UK). It is assumed in this paper that the martensite packets are mainly separated by high-angle misorientation boundaries. Therefore, the equivalent circle diameter obtained from the EBSD data for high-angle misorientation boundaries corresponds to the average martensite 
packet size and the average ferrite grain size. The high angle boundaries are the boundaries with a misorientation angle of $>15^{\circ}$.

TEM investigations were conducted using a JEOL JEM-2100 electron microscope (JEOL Ltd., Akishima, Tokyo, Japan) at an accelerating voltage of $200 \mathrm{kV}$. Thin foils were prepared from the sections parallel to the rolling plane by electropolishing in an electrolyte containing $450 \mathrm{~mL}$ of orthophosphoric acid and $50 \mathrm{~g}$ of chromic anhydride.

Mechanical tensile tests at $300-700{ }^{\circ} \mathrm{C}$ were performed in a vacuum of $\approx 2.7 \times 10^{-3} \mathrm{~Pa}$ by the method of static tensile deformation in the rolling direction at a strain rate of $\approx 2 \times 10^{-3} \mathrm{~s}^{-1}$ on a NIKIMT 1246R-2/2300 high-temperature vacuum testing machine (Experimental Plant "NIKIMP" (Research and Design Institute of Testing Machines, Instruments and Measuring Instruments), Moscow, Russia). We used dog-bone samples with a gage length of $13 \mathrm{~mm}$ and a gage section of $2 \times 1 \mathrm{~mm}^{2}$. Samples were cut parallel to the rolling plane. The scheme of microstructure observation and cutting of samples for tension tests is presented in Supplementary file, Figure S1.

\section{Results}

\subsection{SEM EBSD}

The results of the EBSD studies and their statistical analysis are presented in Figures 1-3. The microstructure of steel after THT (Figure 1) consists of martensitic packets and ferritic grains. The nearly equiaxed former austenite grains (about 10 to 80 microns in size) with martensite packets inside are observed on the orientation and phase maps. The neighboring martensite packets are basically separated by high-angle misorientation boundaries. The lowangle misorientation boundaries observed in Figure $1 \mathrm{~b}$ appear to be mainly the boundaries of the martensitic lamellae blocks making up the packets. At the scanning step of $200 \mathrm{~nm}$, not all lamellae are detected. Higher magnifications, smaller scanning steps (Figure 1d), and TEM methods (see below) allow detecting the fine structure of the martensitic packets. The predominance of blue and yellow colors on the Kernel Average Misorientation (KAM) map (Figure 1c) suggests that the misorientations on the subgrains are quite small (less than $5^{\circ}$ ).

The distribution of grains by misorientations (Figure 1e) clearly shows two peaks corresponding to the low-angle and twin (and similar) misorientations. The latter may be the boundaries between different variants of packet martensite [34]. The fraction of low-angle boundaries after THT is $\approx 55 \%$, and that of twin boundaries is about $15 \%$.

On the phase map, one can see sufficiently coarse (up to several microns) particles of MX type $(M=V, N b, M o ; X=C, N)$, the volume fraction of which is $\approx 0.3 \%$. No nanoscale particles are resolved by the SEM EBSD method. Individual rounded grains of bcc-Fe are also detected, which appear to be $\delta$-ferrite (Figure 1d).

After THT, the average grain size of the martensite packets and ferritic grains (equivalent circle diameter) is $3.1 \mu \mathrm{m}$. The minimum size is $0.7 \mu \mathrm{m}$; the maximum size is more than $30 \mu \mathrm{m}$. It should be noted that in the grain size distribution (Figure 1f), a significant fraction of grains has submicron and micron sizes, and single grains have sizes of tens of microns.

The microstructure of steel after HTMT in the section parallel to the rolling plane (Figure 2) has significant differences from that after THT. Large extended regions with similar orientations are seen on the orientation and phase maps (Figure 2a,b). Inside these regions, there are numerous fine grains (martensitic packets) with an orientation different from that in the coarse-grain regions. The density of low-angle misorientation boundaries increases significantly compared to that after THT (Figure 2b). The fraction of these boundaries (sub-boundaries) in the grain distribution by misorientation angles increases (relative to the THT case) and reaches up to $68 \%$ (Figure 2e). The phase map also shows MX-type particles (Figure 2b). Their volume fraction does not change compared to the THT case. The predominance of green and yellow colors in the KAM map (Figure 2c) indicates an increase in the misorientation angles at the low-angle boundaries compared to the THT case. The fraction of twin boundaries decreases to about $10 \%$. 


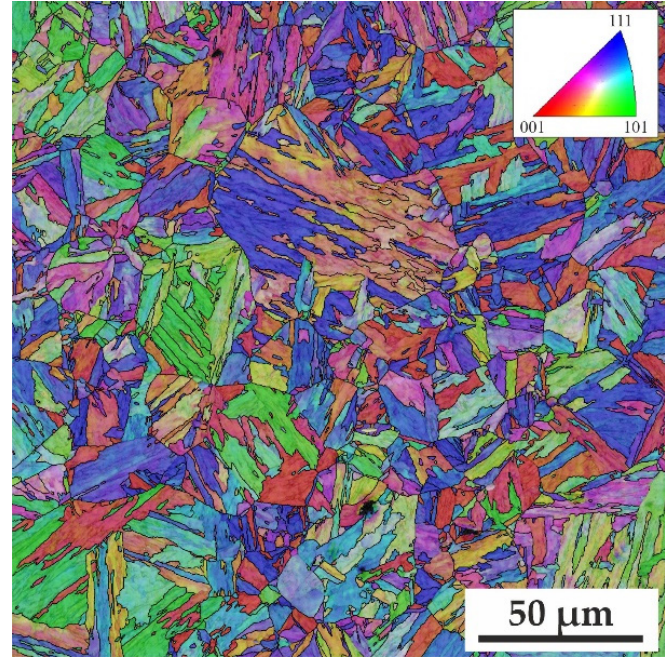

(a)

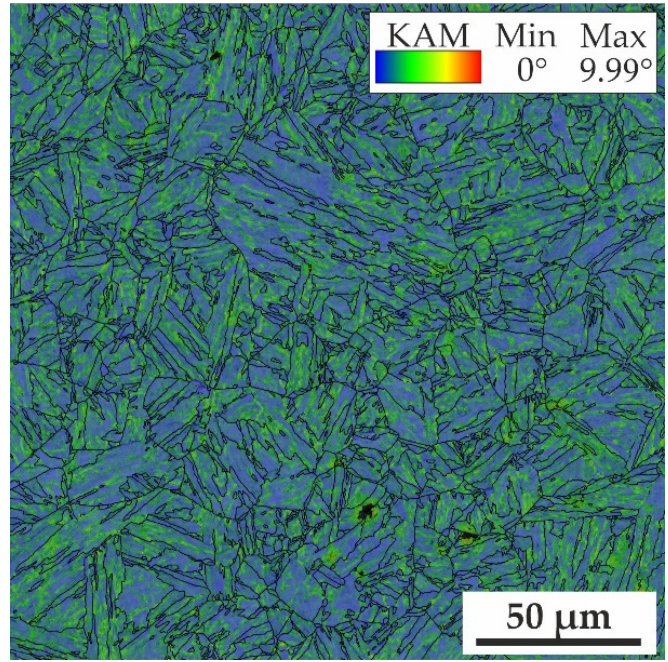

(c)

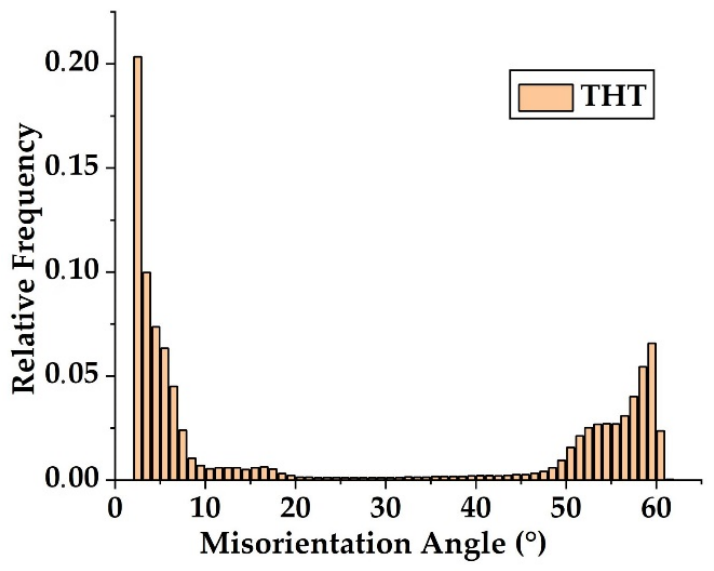

(e)

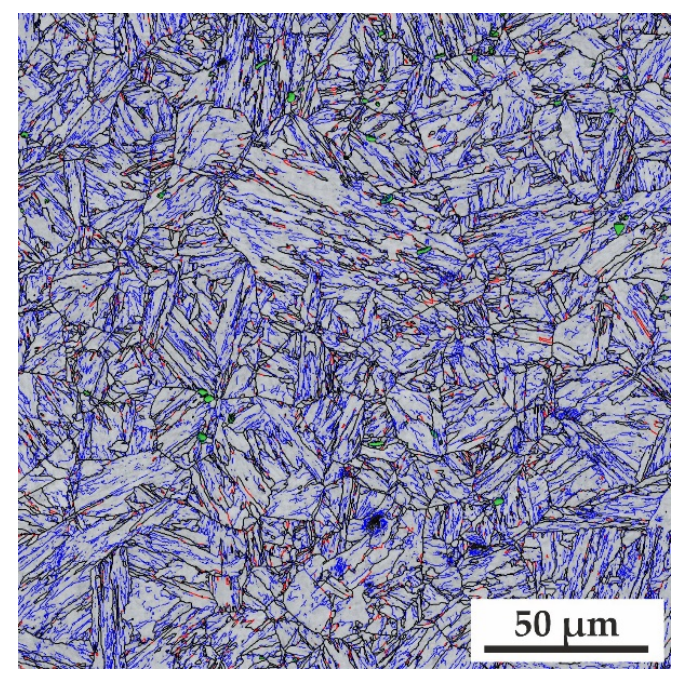

(b)

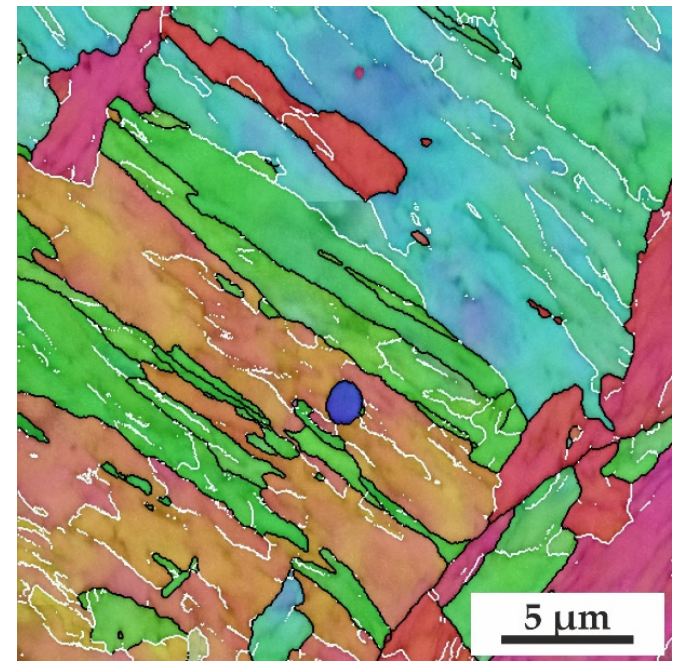

(d)

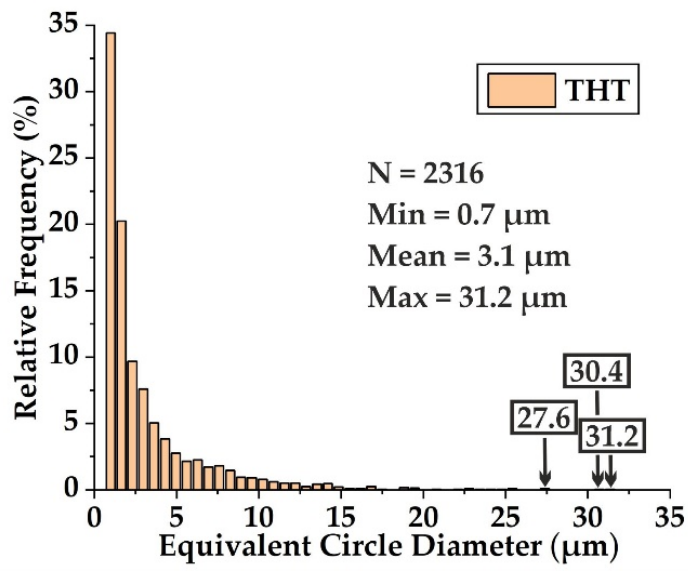

(f)

Figure 1. SEM EBSD images of steel microstructure after THT. Orientation map (a). Phase map, where MX particles are in green color, bcc-Fe is in gray color with high-, low-angle, and twin boundaries denoted by black, blue and red lines, respectively (b). Kernel Average Misorientation (KAM) map (c). Magnified orientation map with high-angle and low-angle boundaries denoted by black and white lines (d). Grain misorientation distribution (e). Histogram of grain size distribution (f). In the other figures, the same boundary coloring is used. 


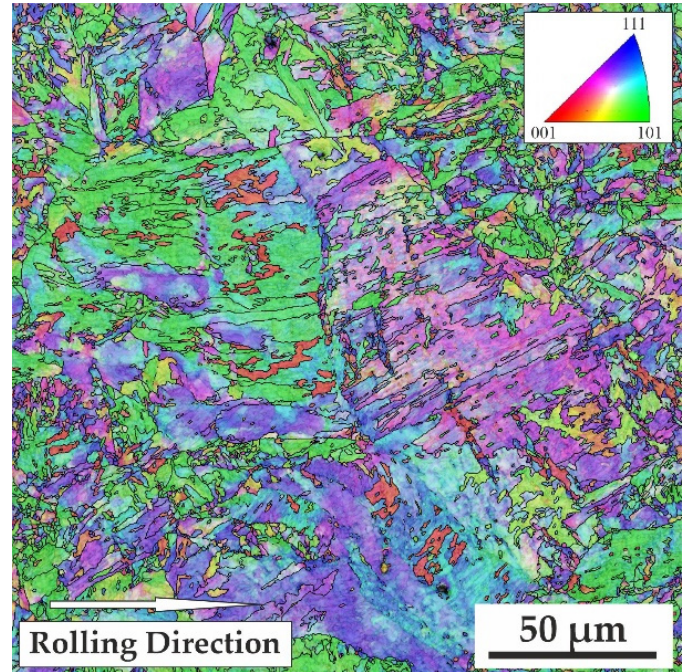

(a)

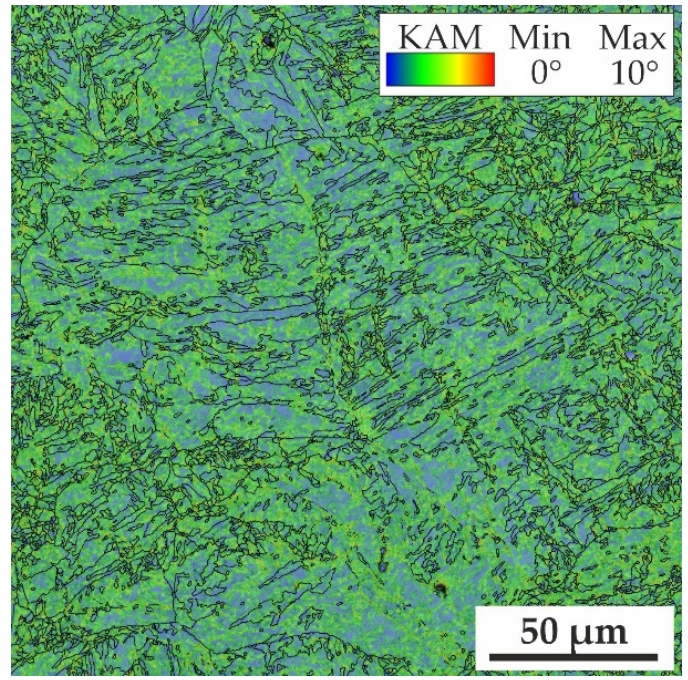

(c)

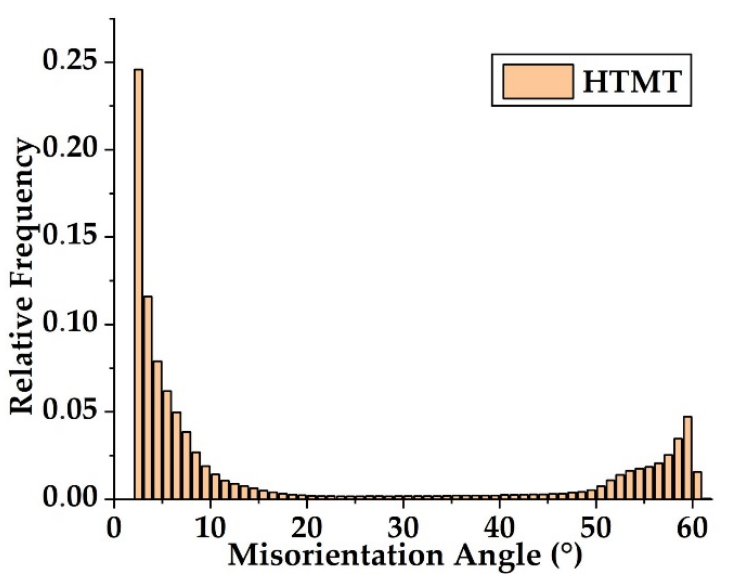

(e)

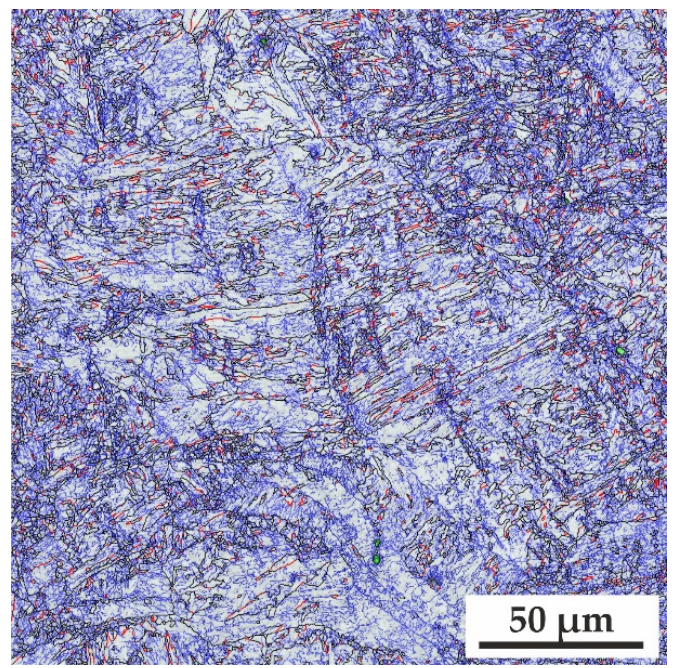

(b)

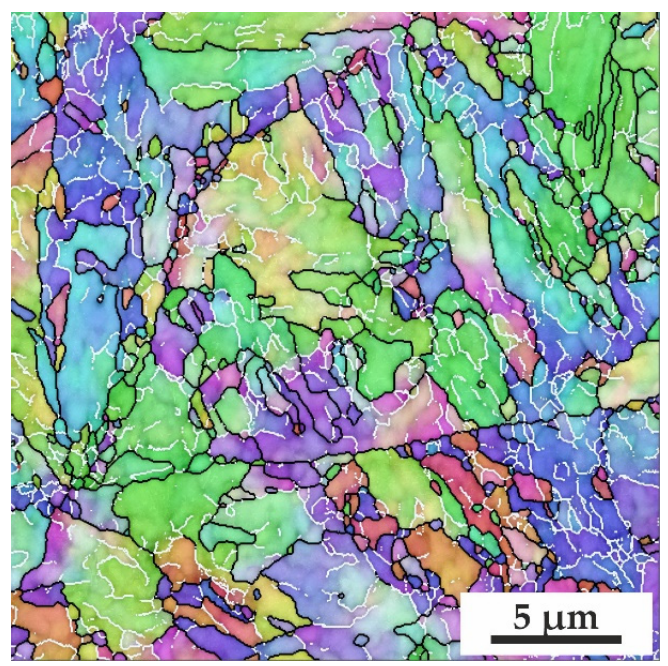

(d)

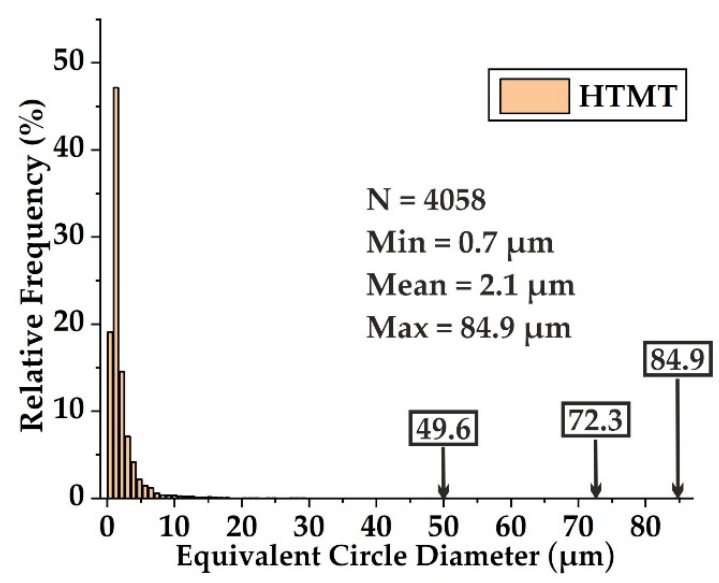

(f)

Figure 2. SEM EBSD images of steel microstructure after HTMT in the section parallel to the rolling plane. Orientation map (a). Phase map (b). KAM map (c). Magnified orientation map (d). Grain misorientation distribution (e). Histogram of grain size distribution (f). 


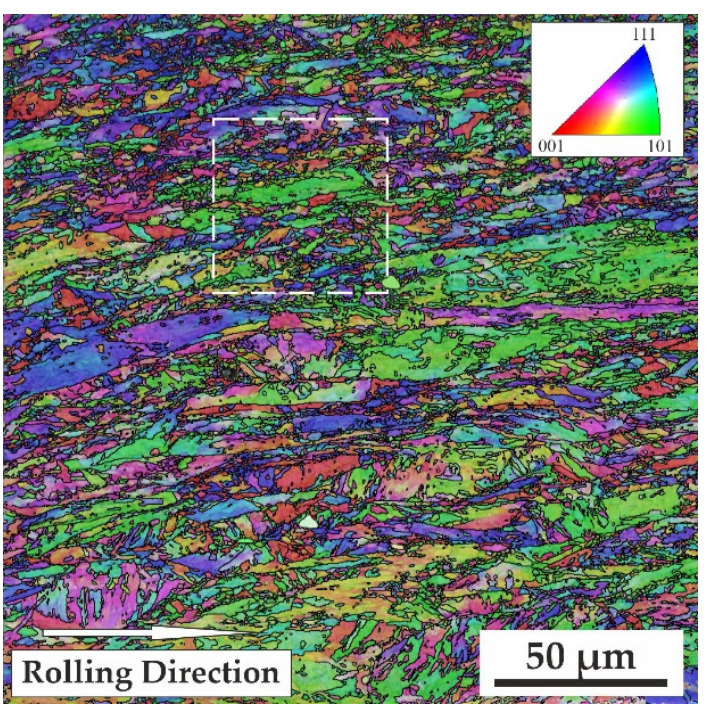

(a)

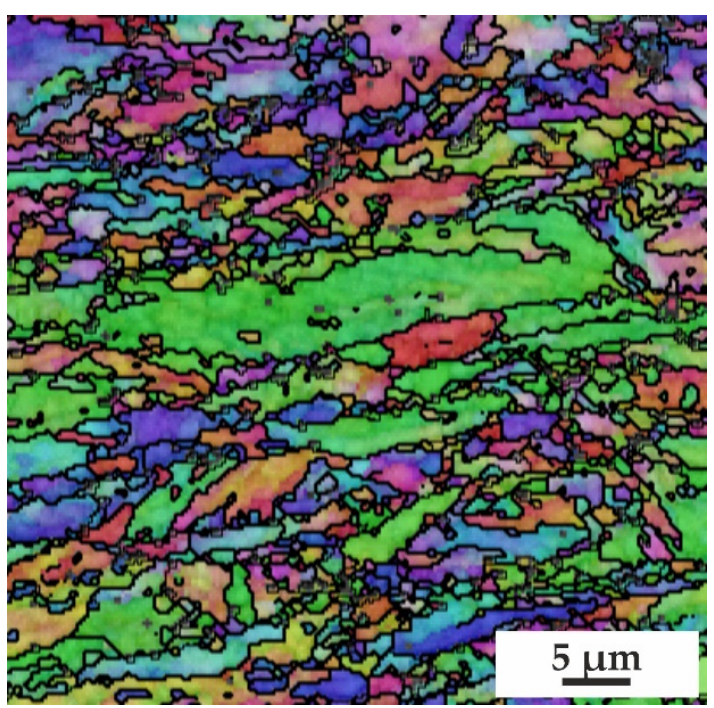

(b)

Figure 3. SEM EBSD images of steel microstructure after HTMT in the longitudinal section. Orientation map with a dashed-line square region (a). Magnified image of this square region (b).

Apparently, the sub-boundaries in these structures are not only martensitic lamellae sub-boundaries but also dislocation substructures formed as a result of work hardening under hot deformation conditions.

After HTMT, in the section parallel to the rolling plane, the average grain size (martensite packets and ferrite grains) is $2.1 \mu \mathrm{m}$, which is about 1.5 times smaller than that in the case of THT. At the same time, the maximum grain size reaches $84.9 \mu \mathrm{m}$, which is almost three times larger than the corresponding sizes after THT. An analysis of the images (Figure 2a,d) and the grain size distribution (Figure 2f) suggests that the grains of micron and submicron sizes and somewhat larger grains of tens of microns are formed in this section.

Investigations of the steel microstructure after HTMT in the longitudinal section (Figure 3) showed the presence of grains elongated in the rolling direction and significantly flattened in the direction normal (ND) to the rolling plane. In ND, their sizes do not exceed $10 \mu \mathrm{m}$. Many micron and submicron martensitic packets, or ferrite grains, are observed inside coarse grain and at their boundaries, just as in the section parallel to the rolling plane. Some of them have nearly equiaxed shapes. (Figure $3 b$ ).

The analysis of statistical data indicates that the average grain size (equivalent circle diameter) in this section is $1.4 \mu \mathrm{m}$, the minimum size is $0.6 \mu \mathrm{m}$, and the maximum size is $19.6 \mu \mathrm{m}$. These values are smaller than the corresponding values in the section parallel to the rolling plane. The submicron grains dominate in the grain size distribution. In the longitudinal section, the fraction of low-angle boundaries is $\approx 52 \%$, which is smaller than the corresponding values in the section parallel to the rolling plane.

Thus, based on the SEM EBSD studies in two sections, it is justified that the hot deformation under HTMT results in the formation of a pancake structure presented by the martensite packets and ferrite grains flattened in the rolling plane and elongated in the rolling direction. The average grain size of this structure (martensite packets and ferritic grains) is 1.5-2 times smaller than the corresponding value after THT. The maximum size (equivalent circle diameter) of individual grains in the section parallel to the rolling plane increases significantly (to more than 80 microns), while in the section perpendicular to the rolling plane, the maximum size does not exceed 20 microns. As a result of hightemperature deformation, besides the boundaries between the martensitic lamellae, many new low-angle boundaries are formed, and the misorientation at the sub-boundaries of the martensitic lamellae increases compared to the corresponding values after THT. 


\subsection{SEM of Etched Samples}

The studies of the microstructure features of the etched steel samples after THT and HTMT showed the presence of a large number of coarse-dispersed carbide particles mainly of submicron sizes on the steel surface (Figure 4). The SE images (in secondary electrons) show the particles that are detectable by the characteristic contrast as a result of their selective etching. In BSE images (in back-scattered electrons), one can distinguish between "gray" particles precipitated predominantly at the grain and subgrain boundaries and "white" particles inside the grains. A local elemental analysis (see Supplementary file, Figure S2) showed that the Cr content in the particles of the first type exceeds the corresponding value for the matrix (Table 1). Based on these data and [12,15,20,22-24], the particles are identified as $\mathrm{M}_{23} \mathrm{C}_{6}$ carbides $\left((\mathrm{Fe}, \mathrm{Cr})_{23} \mathrm{C}_{6}\right)$. The particles of the second type are MX-type carbonitrides $(\mathrm{M}-\mathrm{Nb}, \mathrm{Mo}, \mathrm{X}-\mathrm{C}, \mathrm{N})$. The estimates of the volume fraction of micron and submicron particles based on SEM images showed that above processing has almost no effect on their volume fractions. After THT and HTMT, the volume fraction of $\mathrm{M}_{23} \mathrm{C}_{6}$ particles is $\approx 5.8$ and $5.6 \%$, and the volume fraction of MX type particles is $\approx 0.11$ and $0.15 \%$, respectively. For the latter particles, those values are somewhat lower than that determined by the SEM EBSD $(\approx 0.3 \%)$. The $\mathrm{M}_{23} \mathrm{C}_{6}$ type particles are difficult to distinguish by this method because they have submicron sizes and, in many cases, precipitate at the boundaries of structural elements (grains and subgrains).

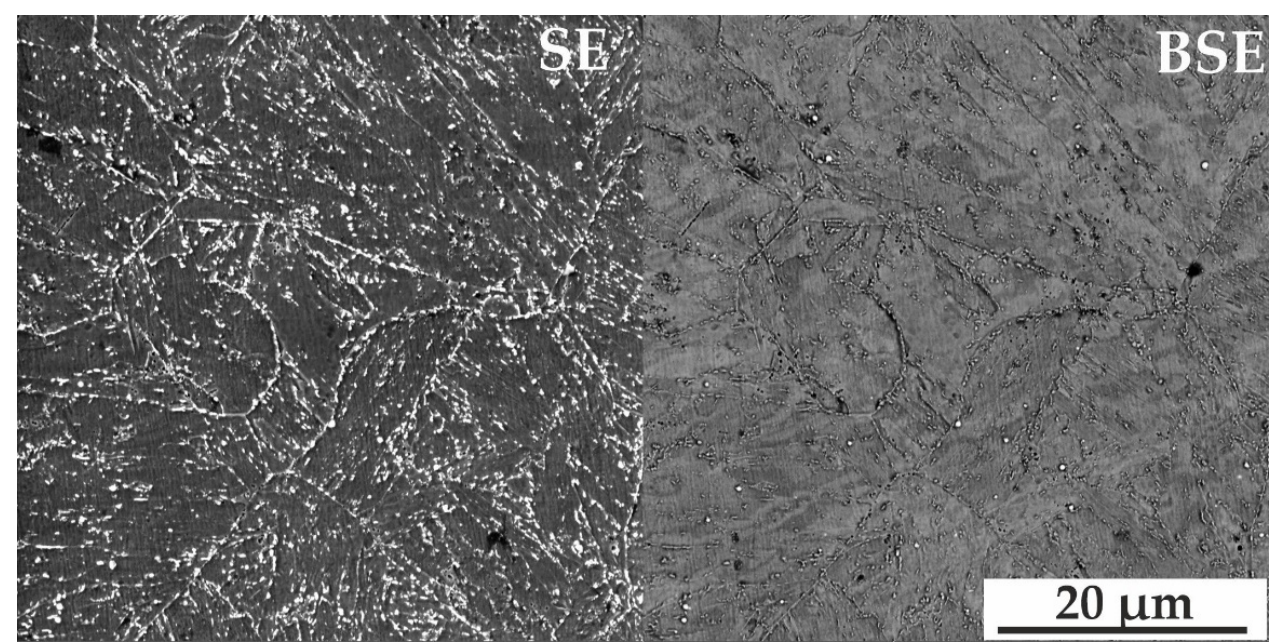

(a)

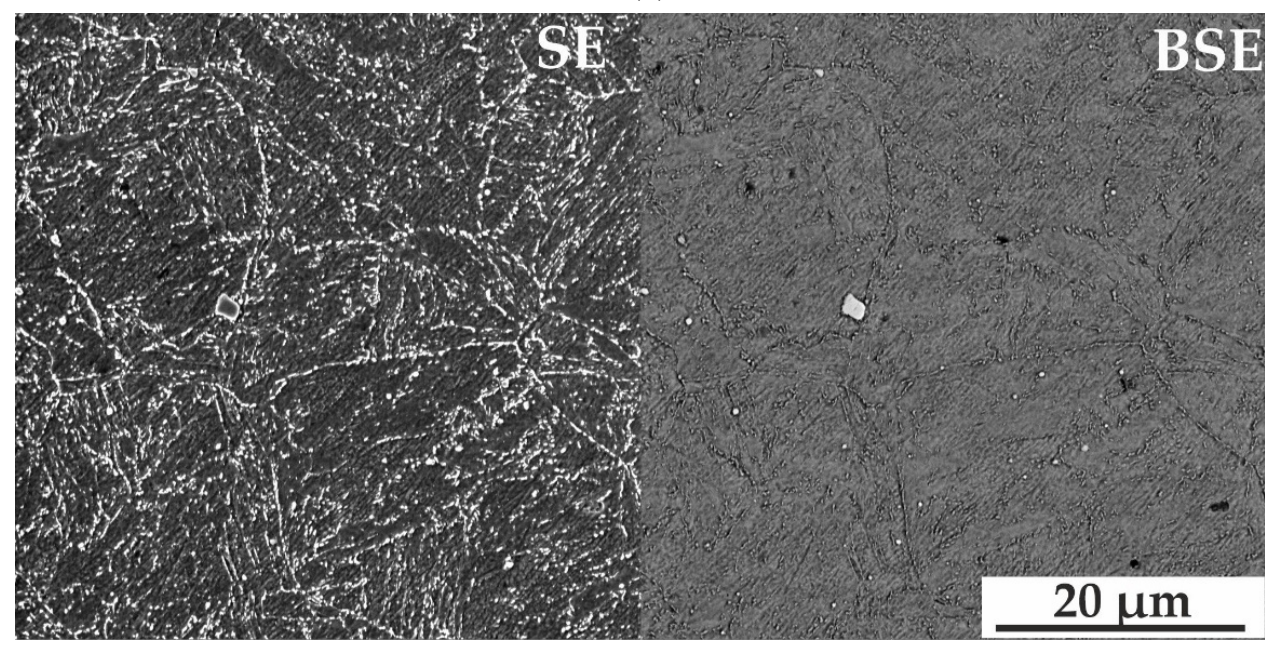

(b)

Figure 4. SEM images of etched steel microstructure after THT (a) and HTMT (b), SE images (left) and BSE images (right). 
It should be noted that not all carbide and carbonitride particles could be detected by SEM of the etched samples. Nanosized (from 5 to 100-200 nm) particles are indistinguishable by this method. Moreover, the contrast on the etched particles can include wider areas, capturing the matrix. This can lead to an overestimation of the volume fractions of particles. Largely this applies to the $\mathrm{M}_{23} \mathrm{C}_{6}$ type particles. These particles locate predominantly along the grain and subgrain boundaries, and the contrast in the particle image may include the contrast at the etched boundaries and sub-boundaries.

\subsection{TEM}

TEM and STEM images of steel microstructure after THT and HTMT are shown in Figure 5 and Figure S3 in Supplementary file. The images contain tempered martensite lamellae, coarse-dispersed (50-150 nm in size) particles of $\mathrm{M}_{23} \mathrm{C}_{6}$ type and fine-dispersed particles of MX type (5-20 nm). The type of the particles was determined by the interplanar spaces in the selected area electron diffraction (SAED) patterns and by the local elemental analysis (Figure S3, Supplementary file). Inside the martensitic lamellae, a dislocation substructure is found (Figure $5 a, b)$.

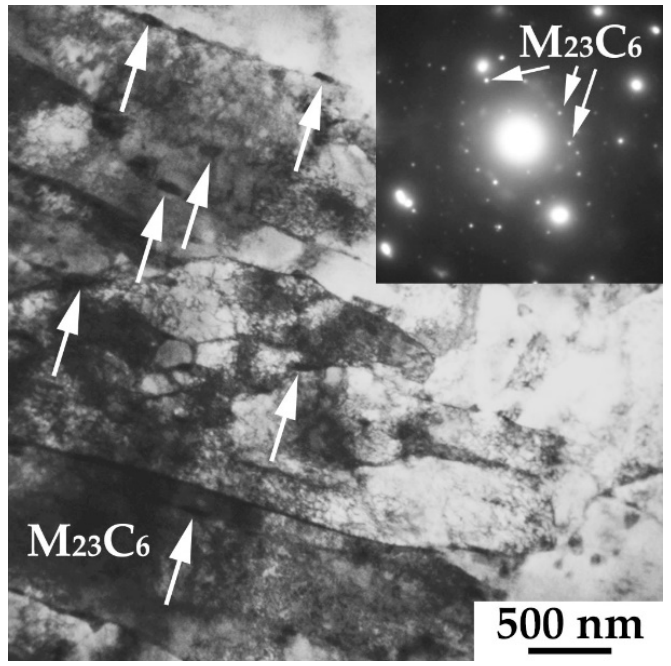

(a)

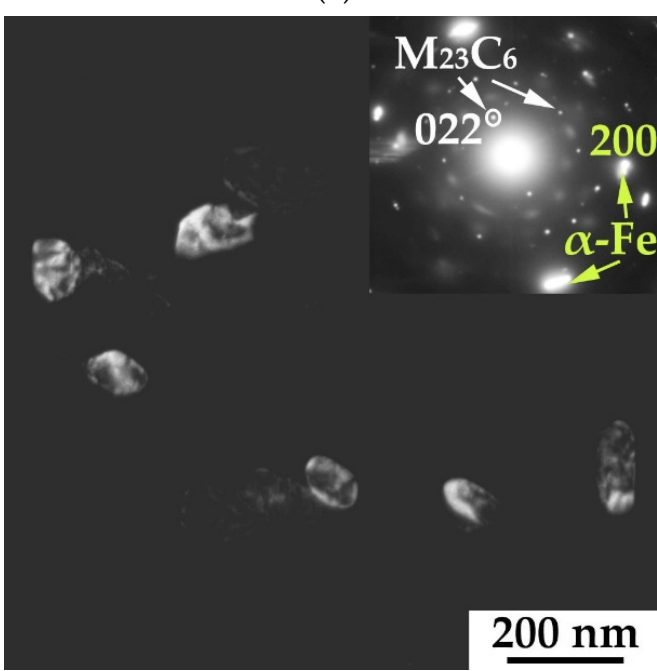

(c)

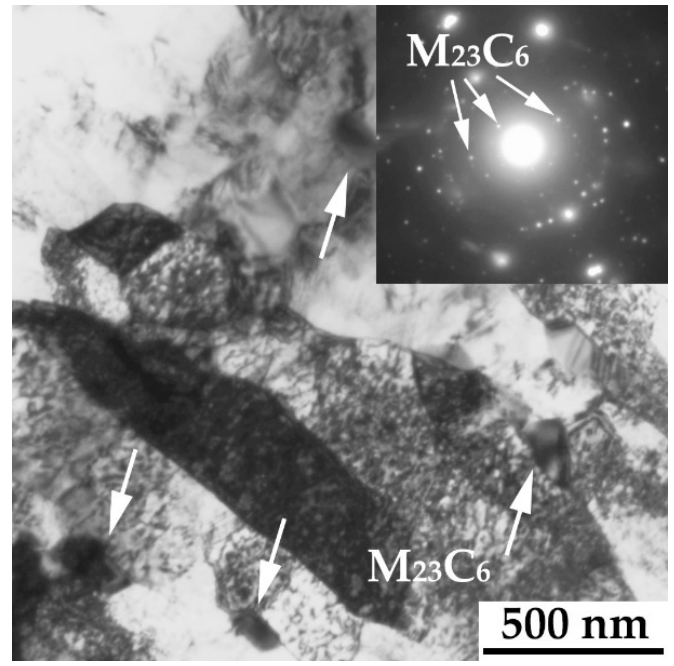

(b)

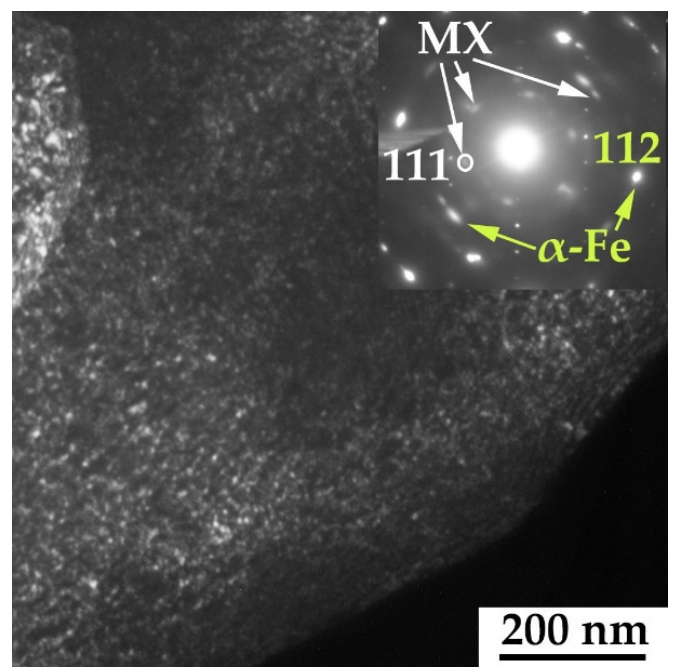

(d)

Figure 5. TEM images of steel microstructure after THT (a) and HTMT (b-d). (a,b) - bright field images with the corresponding selected area electron diffraction (SAED) patterns, (c,d)—dark-field images with the corresponding SAED patterns in reflections of $\mathrm{M}_{23} \mathrm{C}_{6}$ and $\mathrm{MX}$ particles, respectively. 
Nanoscale MX type particles are observed to pin the dislocations. These structural elements are characteristic of ferritic-martensitic steels $[12,15,17,25]$. The microstructure of EP-823 steel after THT and HTMT is qualitatively similar. The differences mainly concern the morphology of structural elements, their size, dislocation density increased after HTMT, as well as the location and morphology of coarse carbides of the $\mathrm{M}_{23} \mathrm{C}_{6}$ type. THT is characterized by the preferential location of $\mathrm{M}_{23} \mathrm{C}_{6}$ carbides at the boundaries of martensitic lamellae and ferrite grains (Figure 5a), [15,17,24]. These carbides have a predominantly elongated lenticular shape. There were no differences in the average sizes of these particles after both treatments. The $\mathrm{M}_{23} \mathrm{C}_{6}$ particles precipitate during tempering after hot deformation and can nucleate on dislocation sub-boundaries formed as a result of HTMT.

In the present work, no differences in the sizes and volume fractions of nanosized particles of the MX type after THT and HTMT were detected. A quantitative estimation of the particle volume fractions is difficult due to their small $(5-20 \mathrm{~nm})$ size and their possible observation in the thin foil regions only. In spite of this, the increase in the volume fraction of dispersed particles as a result of HTMT of ferritic-martensitic steels is noted in many works [11,12,15-17].

\subsection{Mechanical Properties}

The results of the studies of short-term mechanical properties of steel EP-823 after THT and HTMT under tensile testing in the temperature range from 20 to $700{ }^{\circ} \mathrm{C}$ are shown in Figure 6.

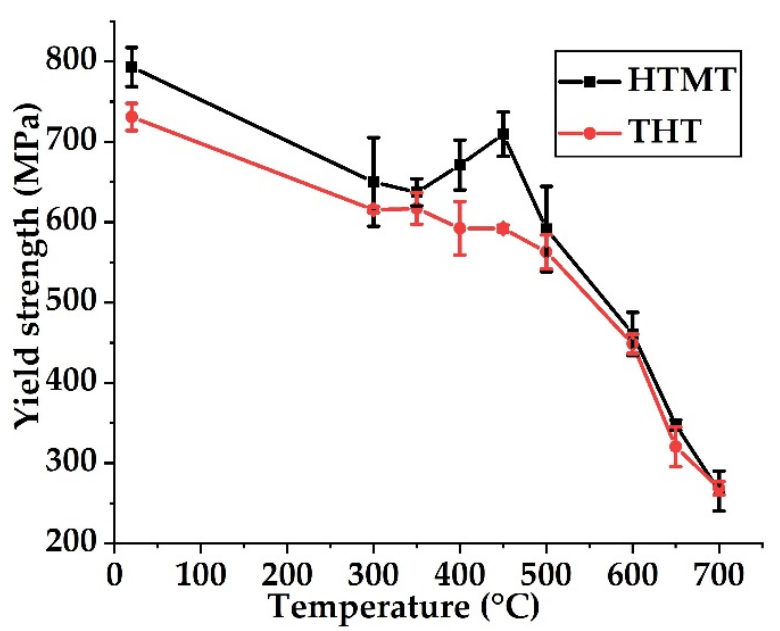

(a)

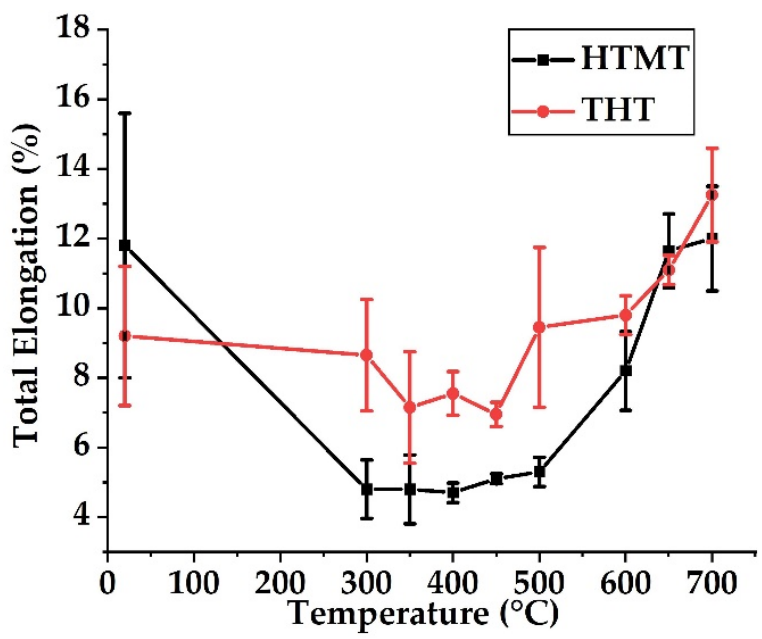

(b)

Figure 6. Variation of mechanical properties of EP-823 steel with temperature for THT and HTMT. Yield strength (a), total elongation (b).

An analysis of these curves shows a qualitatively similar temperature dependence of the yield strength and elongation to failure for THT and HTMT, except for some special features. The temperature intervals of the variation of mechanical properties are similar for many ferritic-martensitic steels $[4,16,24,35]$. On the curves of dependence of the yield strength and elongation on the tensile test temperature for steel EP-823, several characteristic temperature intervals can be distinguished:

- 20 to $300{ }^{\circ} \mathrm{C}$ - the interval of gradual (compared with the interval of higher temperatures) decline of the yield strength for both treatments. The elongation at this decrease is insignificant for THT and falls down after HTMT relative to the corresponding value at $20^{\circ} \mathrm{C}$;

- $\quad 300$ to $500{ }^{\circ} \mathrm{C}$ - the interval of a slight decrease in the yield strength with increasing temperature for THT and an increase in the yield strength at $400-450{ }^{\circ} \mathrm{C}$ (with a maxi- 
mum at $450{ }^{\circ} \mathrm{C}$ ) for HTMT. Elongation to failure in this temperature range is minimal $(\approx 4-5 \%)$ after HTMT. After THT, the minimum values of elongation are observed at $350-450{ }^{\circ} \mathrm{C}, \approx 7-7.5 \%$, which exceeds the corresponding values after HTMT;

- $\quad 500$ to $700{ }^{\circ} \mathrm{C}$ - the interval of a significant decrease of the yield strength and an increase of elongation to failure with increasing temperature for both treatments.

After HTMT, there is an increase in the yield strength in the temperature range from 20 to $650{ }^{\circ} \mathrm{C}$ relative to the corresponding values after the THT. At $700{ }^{\circ} \mathrm{C}$, the yield strength values after both treatments are almost the same. The maximum difference in the yield strength is observed in the temperature range of $400-450{ }^{\circ} \mathrm{C}$ and is found to be $80-120 \mathrm{MPa}$. The elongation after HTMT is several percent lower than the corresponding values after THT, except for the values at 20 and $650{ }^{\circ} \mathrm{C}$.

For ferritic-martensitic steels $[4,6,35]$, there is a plateau on the yield strength plot versus the temperature in the range of $300-500{ }^{\circ} \mathrm{C}$, which is characterized by its almost invariable value with increasing test temperature. The elongation to failure in this case decreases relative to the values at other tensile temperatures. This yield strength and elongation behavior is characteristic for dynamic strain aging (DSA) [4]. Figure 7 shows the tensile stress curves of steel in the temperature range of $400-450{ }^{\circ} \mathrm{C}$ after the two treatments. After THT, a serrated flow is observed only in the tensile curve at $450{ }^{\circ} \mathrm{C}$; at $400{ }^{\circ} \mathrm{C}$, the flow curve is without any features. HTMT has a significant effect on the behavior of EP-823 steel in the DSA region, which shows itself in an increase in the yield strength by $80-100 \mathrm{MPa}$ at $400-450{ }^{\circ} \mathrm{C}$. The tensile curves at these temperatures clearly show a serrated flow. The elongation of steel after HTMT at these temperatures has minimal values.

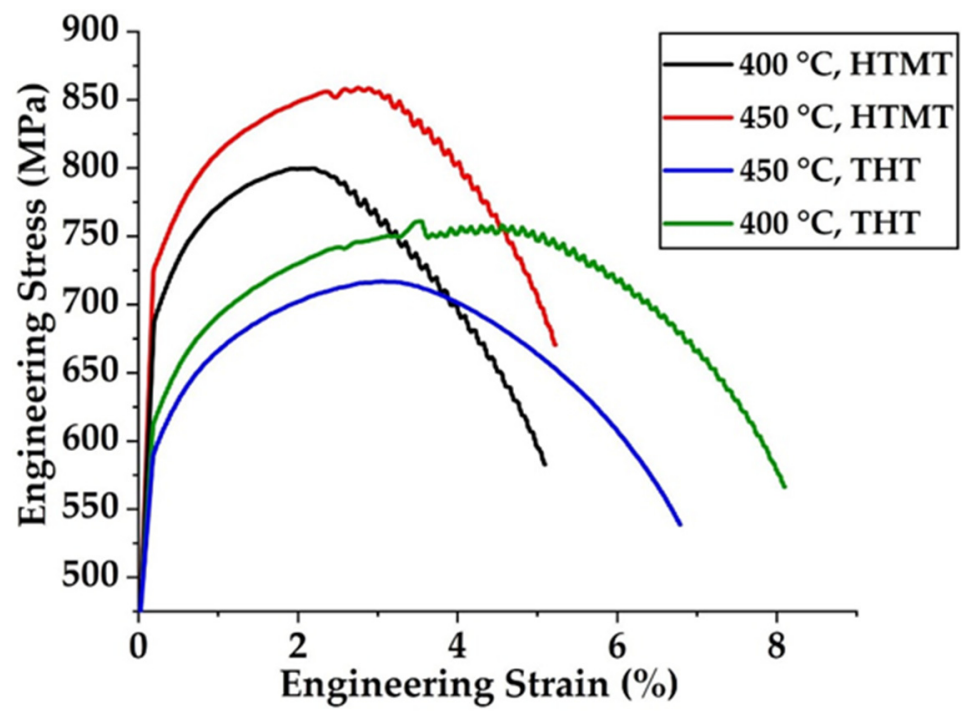

Figure 7. Flow curves of steel after THT and HTMT at 400 and $450{ }^{\circ} \mathrm{C}$.

\section{Discussion}

The features of microstructure formation under HTMT of the EP-823 steel are typical for ferritic-martensitic steels under this type of treatment [4,6,15-17]. Notably, the microstructure of these types of steel was mainly investigated in one section. In the present work, the features of structure and substructure in two sections-parallel to the rolling plane and in the longitudinal section are demonstrated. It is shown that the tempered martensite packets and ferritic grains are pancake-shaped, elongated in the rolling direction and flattened in the rolling plane. The average size of the martensite packets and ferritic grains after HTMT decreases by 1.5-2 factors (relative to the corresponding value after THT), but their maximum sizes in the section parallel to the rolling plane increase. As a result of HTMT, the misorientation angles on the low-angle boundaries of martensitic lamellae increase, new low-angle boundaries are formed, and the dislocation density increases (as can be seen in the KAM maps, Figure 2c compared to Figure 1c). 
The increase in the volume fraction of dispersed particles as a result of thermomechanical treatments has been noted in many works [6,15-17]. In the present work, no qualitative and quantitative differences in the features of the carbide subsystem of EP-823 steel after HTMT and THT were revealed. The volume fractions and sizes of both coarse-dispersed carbides $\mathrm{M}_{23} \mathrm{C}_{6}$ and $\mathrm{MX}$-type carbonitrides, as well as fine-dispersed MX-type particles, do not practically depend on the treatment regime. This may be due to both the features of the elemental composition of steel (the content and type of carbide-forming elements) and the HTMT parameters.

The features of grain structure and substructure of EP-823 steel after HTMT control the increase in strength and the decrease in plastic properties practically in the whole temperature range of $20-700{ }^{\circ} \mathrm{C}$ compared to the corresponding values after THT. At the same time, the main mechanisms of steel hardening are the reduction of the average size of martensitic packets and ferritic grains and the substructural strengthening. Dispersed nanoscale particles pining the dislocation substructure also play an important role in maintaining the high strength properties of steel. An increase in the strength in a wide range of test temperatures as a result of HTMT has been noted for many ferritic-martensitic steels $[4,14-19,23]$, while some authors [4] report an increase in ductility due to an increase in grain sizes.

It was noted [4] that the yield strength values in the DSA region reach a plateau and practically do not depend on the test temperature of ferritic-martensitic steels. In the EP-823 steel after HTMT, in the DSA temperature range $\left(400-450{ }^{\circ} \mathrm{C}\right)$, there is an increase in the yield strength. The features of the structural-phase state of steel, apparently, cause a significant effect on the plastic flow of steel in the DSA region after HTMT. The high density of the substructure formed as a result of hot deformation may facilitate the nucleation of dispersed particles under tensile deformation in the DSA temperature interval. In this case, the temperature interval for DSA after HTMT is shifted relative to the corresponding temperatures after THT. The serrated flow after HTMT is observed at $400{ }^{\circ} \mathrm{C}$ and is absent after THT at this temperature. At tensile test temperatures of $300-500{ }^{\circ} \mathrm{C}$, the precipitation of dispersed particles contributes to an increase in the yield strength and a decrease in the ductility because the increased density of particles is an obstacle to the dislocation motion. At higher tensile temperatures $\left(600-700^{\circ} \mathrm{C}\right)$, the gliding dislocations become capable of overcoming dispersed particles as a result of climbing. This leads to a decrease in the yield strength and an increase in the elongation at these temperatures. At $700{ }^{\circ} \mathrm{C}$, the effect of the high substructure density created by HTMT is practically leveled.

\section{Conclusions}

The features of the grain structure and substructure of ferritic-martensitic steel EP823 after HTMT with plastic deformation in the austenitic region compared with similar features after THT have been studied. It has been shown that HTMT leads to the formation of a pancake structure with the grains elongated in the rolling direction and flattened in the rolling plane and a 1.5-2 times decrease in the average size of martensite packets and ferrite grains (compared to the corresponding values after THT). The misorientations at the sub-boundaries of martensitic lamellae increase, new dislocation substructures are formed, and the dislocation density increases. The sizes and volume fractions of the coarse and fine dispersed particles of carbide and carbonitride do not practically depend on the processing regime. The microstructural features revealed in this study determine the increase in the yield strength and the elongation reduction practically in the whole temperature range $\left(20-700{ }^{\circ} \mathrm{C}\right)$ of the tensile tests. The HTMT has a significant effect on steel behavior in the DSA region. In this temperature range, there is an increase in the yield strength, and the ductility decreases significantly while maintaining satisfactory values. The features of dispersed particles precipitation in the microstructure with the increasing dislocation density under tensile tests in the DSA temperature range determine this behavior. 
Supplementary Materials: The following supporting information can be downloaded at: https: / / www.mdpi.com/article/10.3390/met12010079/s1, Figure S1: The scheme of sample cutting for microstructure observation and tension tests; Figure S2: SEM images of etched steel microstructure. SE image (a); BSE image (b); local elemental analysis in point 1-3 respectively (c-e); Figure S3: STEM image and elemental maps.

Author Contributions: Conceptualization, I.L. and K.A.; methodology, I.L.; formal analysis, E.M. and V.L.; investigation, N.P., S.A., K.A. and E.M.; writing-original draft preparation, I.L.; writingreview and editing, N.P. and I.L.; visualization, K.A. and V.L.; supervision, V.C. and M.L.-S.; project administration, I.L. All authors have read and agreed to the published version of the manuscript.

Funding: The work was performed according to the Government Research Assignment for the Institute of Strength Physics and Materials Science of the Siberian Branch of the Russian Academy of Sciences (ISPMS SB RAS), project No. FWRW-2021-0008.

Institutional Review Board Statement: Not applicable.

Informed Consent Statement: Not applicable.

Data Availability Statement: Not applicable.

Acknowledgments: The investigations have been carried out using the equipment of Share Use Centre "Analytical Center for Geochemistry of Natural Systems" of Tomsk State University and the equipment of Share Use Centre "Nanotech" of the Institute of Strength Physics and Materials Science SB RAS.

Conflicts of Interest: The authors declare no conflict of interest.

\section{References}

1. Odette, R.G.; Zinkle, S.J. Structural Alloys for Nuclear Energy Applications; Elsevier: Amsterdam, The Netherlands, 2019; p. 655, ISBN 9780123970466. [CrossRef]

2. Yvon, P. Structural Materials for Generation IV Nuclear Reactors; Elsevier: Amsterdam, The Netherlands, 2017; p. 664, ISBN 9780081009062. [CrossRef]

3. Cabet, C.; Dalle, F.; Gaganidze, E.; Henry, J.; Tanigawa, H. Ferritic-martensitic steels for fission and fusion applications. J. Nucl. Mater. 2019, 523, 510-537. [CrossRef]

4. Prakash, P.; Vanaja, J.; Srinivasan, N.; Parameswaran, P.; Nageswara Raon, G.V.S.; Laha, K. Effect of thermo-mechanical treatment on tensile properties of reduced activation ferritic-martensitic steel. Mater. Sci. Eng. A 2018, 724, 171-180. [CrossRef]

5. Tan, L.; Hoelzer, D.T.; Busby, J.T.; Sokolov, M.A.; Klueh, R.L. Microstructure control for high strength 9Cr ferritic-martensitic steels. J. Nucl. Mater. 2012, 422, 45-50. [CrossRef]

6. Tan, L.; Yang, Y.; Busby, J.T. Effects of alloying elements and thermomechanical treatment on 9Cr Reduced Activation FerriticMartensitic (RAFM) steels. J. Nucl. Mater. 2013, 442, 513-517. [CrossRef]

7. Hollner, S.; Piozin, E.; Mayr, P.; Caës, C.; Tournié, I.; Pineau, A.; Fournier, B. Characterization of a boron alloyed 9Cr3W3CoVNbBN steel and further improvement of its high-temperature mechanical properties by thermomechanical treatments. J. Nucl. Mater. 2013, 441, 15-23. [CrossRef]

8. Totemeier, T.C.; Tian, H.; Simpson, J.A. Effect of Normalization Temperature on the Creep Strength of Modified 9Cr-1Mo Steel. Metall. Mater. Trans. A 2006, 37, 1519-1525. [CrossRef]

9. Liu, J.; Liu, W.; Hao, Z.; Shi, T.; Kang, L.; Cui, Z.; Yun, D. Effects of Silicon Content and Tempering Temperature on the Microstructural Evolution and Mechanical Properties of HT-9 Steels. Materials 2020, 13, 972. [CrossRef] [PubMed]

10. Qiu, G.; Zhan, D.; Li, C.; Yang, Y.; Qi, M.; Jiang, Z.; Zhang, H. Influence of Inclusions on the Mechanical Properties of RAFM Steels Via $Y$ and Ti Addition. Metals 2019, 9, 851. [CrossRef]

11. Ma, T.; Hao, X.; Wang, P. Effect of Heat Treatments on Microstructural Evolution and Tensile Properties of 15Cr12MoVWN Ferritic/Martensitic Steel. Metals 2020, 10, 1271. [CrossRef]

12. Xu, Z.; Shen, Y.; Shang, C.; Huang, X. Precipitate phases in ferritic/martensitic steel P92 after thermomechanical treatment. J. Nucl. Mater. 2018, 509, 355-365. [CrossRef]

13. Shen, Y.; Shang, Z.; Xu, Z.; Liu, W.; Huang, X.; Liu, H. The nature of nano-sized precipitates in ferritic/martensitic steel P92 produced by thermomechanical treatment. Mater. Charact. 2016, 119, 13-23. [CrossRef]

14. Wu, X.; Ukai, S.; Leng, B.; Oono, N.; Hayashi, S.; Sakasegawa, H.; Tanigawa, H. Hot-rolling of reduced activation 8CrODS ferritic steel. J. Nucl. Mater. 2013, 443, 59-65. [CrossRef]

15. Klueh, R.L.; Hashimoto, N.; Maziasz, P.J. New nano-particle-strengthened ferritic/martensitic steels by conventional thermomechanical treatment. J. Nucl. Mater. 2007, 367-370, 48-53. [CrossRef] 
16. Hollner, S.; Fournier, B.; Pendu, J.L.; Cozzika, T.; Tournié, I.; Brachet, J.-C.; Pineau, A. High-temperature mechanical properties improvement on modified 9Cr-1Mo martensitic steel through thermomechanical treatments. J. Nucl. Mater. 2010, 405, 101-108. [CrossRef]

17. Tan, L.; Busby, J.T.; Maziasz, P.J.; Yamamoto, Y. Effect of thermomechanical treatment on 9Cr ferritic-martensitic steels. J. Nucl. Mater. 2013, 441, 713-717. [CrossRef]

18. Vivas, J.; San-Martin, D.; Cabalero, F.G.; Capdevila, C. High-chromium (9-12cr) steels: Creep enhancement by conventional thermomechanical treatments. Met. Heat Treatments 2020. [CrossRef]

19. Mao, C.; Liu, C.; Liu, G.; Yu, L.; Li, H.; Dong, J.; Liu, Y. The correlation between the microstructural parameters and mechanical properties of reduced activation ferritic-martensitic (RAFM) steel: Influence of roll deformation and medium temperature tempering. Metall. Mater. Trans. A 2020, 52, 119-128. [CrossRef]

20. Liu, C.; Zhao, Q.; Liu, Y.; Wei, C.; Li, H. Microstructural evolution of high Cr ferrite/martensite steel after deformation in metastable austenite zone. Fusion Eng. Des. 2017, 125, 367-371. [CrossRef]

21. Zhang, G.; Zhou, Z.; Sun, H.; Zou, L.; Wang, M.; Li, S. Hot deformation behavior and processing map of a $9 \mathrm{Cr}$ ferritic/martensitic ODS steel. J. Nucl. Mater. 2014, 455, 139-144. [CrossRef]

22. Polekhina, N.A.; Litovchenko, I.Y.; Tyumentsev, A.N.; Kravchenko, D.A.; Chernov, V.M.; Leont'eva-Smirnova, M.V. Effect of hightemperature thermomechanical treatment in the austenite region on microstructure and mechanical properties of low-activated 12\% chromium ferritic-martensitic steel EK-181. Tech. Phys. 2017, 62, 736-740. [CrossRef]

23. Yan, B.; Liu, Y.; Wang, Z.; Liu, C.; Si, Y.; Li, H.; Yu, J. The effect of precipitate evolution on austenite grain growth in RAFM steel. Materials 2017, 10, 1017. [CrossRef]

24. Almaeva, K.V.; Litovchenko, I.Y.; Polekhina, N.A. Microstructure, mechanical properties and fracture of EP-823 ferritic/martensitic steel after high-temperature thermomechanical treatment. Rus. Phys. J. 2020, 63, 803-808. [CrossRef]

25. Zhou, J.; Shen, Y.F.; Xue, W.Y.; Jia, N. Hot-deformation induced static recrystallization and nano-MX precipitation in a low activation martensitic steel. J. Nucl. Mater. 2021, 556, 153190. [CrossRef]

26. Shruti, P.; Sakthivel, T.; Nageswara Rao, G.V.S.; Laha, K.; Srinivasa Rao, T. The role of thermomechanical processing in creep deformation behavior of modified 9Cr-1Mo steel. Metall. Mater. Trans. A 2019, 50, 4582-4593. [CrossRef]

27. Zhou, X.; Liu, Y.; Liu, C.; Yu, L.; Li, H. Austenitizing temperature effects on the martensitic transformation, microstructural characteristics, and mechanical performance of modified ferritic heat-resistant steel. Metall. Mater. Trans. A 2018, $49,3525$. [CrossRef]

28. Almaeva, K.V.; Polekhina, N.A.; Linnik, V.V.; Litovchenko, I.Y. Microstructure and Mechanical Properties of Ferritic-Martensitic Steel EP-823 after High-Temperature Thermomechanical Treatment. AIP Conf. Proc. 2019, 2167, 020013. [CrossRef]

29. Lambrinou, K.; Koch, V.; Coen, G.; Van den Bosch, J.; Schroer, C. Corrosion scales on various steels after exposure to liquid lead-bismuth eutectic. J. Nucl. Mater. 2014, 450, 244-255. [CrossRef]

30. Lu, S.P.; Liang, T.; Li, Y.K.; Li, D.Z.; Rong, L.J.; Li, Y.Y. Microstructure and Mechanical Properties of Simulated Heat-affected Zones of EP-823 Steel for ADS/LFR. J. Mater. Sci. Technol. 2015, 31, 864-871. [CrossRef]

31. Wang, H.; Xiao, J.; Wang, H.; Chen, Y.; Yin, X.; Guo, N. Corrosion Behavior and Surface Treatment of Cladding Materials Used in High-Temperature Lead-Bismuth Eutectic Alloy: A Review. Metals 2021, 11, 364. [CrossRef]

32. Terent'ev, V.F.; Chernov, V.M.; Kolmakov, A.G.; Prosvirnin, D.V.; Kopiev, G.V.; Leont'eva-Smirnova, M.V.; Moroz, K.A.; Antonova, O.S. Fatigue Strength of Ferrite-Martensite 12\% Chromium Steels EK-181, EP-823 and Vanadium Alloy V-4Ti-4Cr. Inorg. Mat. Appl. Res. 2018, 9, 212-220. [CrossRef]

33. Eliseeva, O.I.; Tsisar, V.P. Effect of temperature on the interaction of EP-823 steel with lead melts saturated with oxygen. Mater. Sci. 2007, 43, 230-237. [CrossRef]

34. Pereloma, E.; Edmonds, D. Phase Transformations in Steels: Diffusionless Transformations, High Strength Steels, Modelling and Advanced Analytical Techniques, 2nd ed.; Woodhead Publishing Limited: Cambridge, UK, 2012; p. 680, ISBN 9780857096111. [CrossRef]

35. Polekhina, N.A.; Litovchenko, I.Y.; Tyumentsev, A.N.; Akkuzin, S.A.; Chernov, V.M.; Leont'eva-Smirnova, M.V. Temperature Dependences of Mechanical Properties and Fracture Features of Low-Activation Ferritic-Martensitic EK-181 Steel in a Temperature Range from -196 to $720^{\circ}$ C. Phys. At. Nucl. 2018, 81, 1024-1032. [CrossRef] 